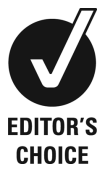

${ }^{1}$ Division of Palliative Medicine, National Cancer Centre, Singapore, Singapore ${ }^{2}$ Department of Occupational Therapist, Bright Vision Hospital, Singapore, Singapore ${ }^{3}$ Department of Senior Medical Social Worker, Bright Vision Hospital, Singapore, Singapore

\section{Correspondence to} Dr L K R Krishna, lalit.krishna@nccs.com.sg

Accepted 23 June 2014

To cite: $\mathrm{R}$ Krishna LK, Yong CYL, Koh SMC. BMJ Case Rep Published online: [please include Day Month Year] doi:10.1136/bcr-2014204780

\title{
The role of palliative rehabilitation in the preservation of personhood at the end of life
}

\author{
L K R Krishna, ${ }^{1}$ C Y L Yong, ${ }^{2}$ S M C Koh ${ }^{3}$
}

\section{SUMMARY}

Progressive advancements in the fields of medicine, oncology and palliative care have seen significant gains in the life expectancy but have also resulted in patients living longer with the burdens of cancer. It is within the sphere of end-of-life care that the role of palliative rehabilitation comes into its own in addressing the effects of increased physical and psychological morbidity that accompany many of these prognostic gains. Focusing on the cancer journey, we highlight the impact of rehabilitative measures on efforts to preserve the personhood of a patient with metastatic renal cell carcinoma and thus maintain her dignity and quality of life and provide her with appropriate and effective holistic care at the end of life. Through employing the Ring Theory of Personhood, the critical role of the complementary aspects of palliative rehabilitation in endof-life care is brought to the fore.

\section{BACKGROUND}

The success of palliative rehabilitation in the preservation of quality of life of terminally ill patients through the maintenance of individual control and mobility even in the face of progressive disease has led to this treatment modality being embraced by many palliative care teams. ${ }^{1-6}$ Palliative rehabilitation, which Dietz defines as being focused on "assist[ing] in symptom control in progressive disease and in its advanced stages" and in "prevent [ing] or minimizing associated complications and optimiz[ing] quality of life" has also a significant impact on the maintenance of dignity and the provision of holistic care underpinned by its influence on the preservation of the personhood of these patients. ${ }^{5-11}$ However before we begin to discuss these elements, a clear understanding of the concept of personhood and how it is conceived within the Ring Theory of Personhood (Ring Theory); is required..$^{8-11}$

While the definition of personhood has until recently been poorly delineated, its role within the maintenance of dignity, quality of life and provision of holistic care at the end of life has been well established. ${ }^{8-11}$ This is particularly evident in palliative rehabilitation. ${ }^{8-11}$ We utilise the Ring Theory, the first clinically evidenced formulation to define personhood within the palliative care setting, to highlight the impact of rehabilitative measures on personhood and thus its influence in the maintenance of dignity, quality of life and the provision of holistic care at the end of life ${ }^{8-11}$

\section{Conceptions of personhood among terminally ill patients}

Employ of Krishna's Ring Theory to highlight the importance placed on functionality and the ability to maintain familial bonds and obligations underpins the advocacy of rehabilitative medicine within the palliative care setting. ${ }^{8-13}$ Briefly the Ring Theory evidences that oncology and palliative care patients see themselves as more than solely reflections of their familial identity, their divine connections with God or their ability to manifest conscious function. ${ }^{8-13}$ Instead according to the Ring Theory, personhood is made up of four interrelated domains that are illustrated in the form of four rings ${ }^{8-11}$ (figure 1).

The inner most ring is called the innate ring. The innate ring embodies the belief that personhood begins from the moment of conception. Innate personhood is formed by virtue of the patient's ties with the divine or by reason of their genetic or their physical human characteristics. ${ }^{8-11}$

Highlighting the inherent inter-relatedness of the four rings within the Ring Theory is the belief that those who have close personal and important relationships with the patient endow innate personhood. At the start of life, these are ties with one's parents. ${ }^{8-11}$

Encapsulating the innate ring is the individual ring that pivots on the patient's ability to maintain conscious function. This includes self-awareness, self-control, communication, cognition, interaction with one's environment and a sense of time, past and future. The individual ring confers on the patient the ability to maintain his or her own personhood. Sustaining one's own personhood begins with the onset of competence and autonomous function. If however the patient becomes incompetent and or essentially not autonomous, personhood reverts to being endowed by those that share close relationships with the patient and who are aware of their values, beliefs, views and goals. This contingency ensures that the now incompetent patient's personhood is maintained in a manner that is most akin to their own conceptions of personhood and specific identity and not defined solely on their sociocultural, religious or familial roles, ties and obligations.

The pivotal relationships that are relied on to define an incompetent's personhood are housed in the relational ring, which encapsulates the individual ring. Here it is critical to state that for the competent and autonomous patient, these relationships need not be solely defined by the presence of familial ties and can often include close friends and 
Figure 1 The Ring Theory of Personhood.

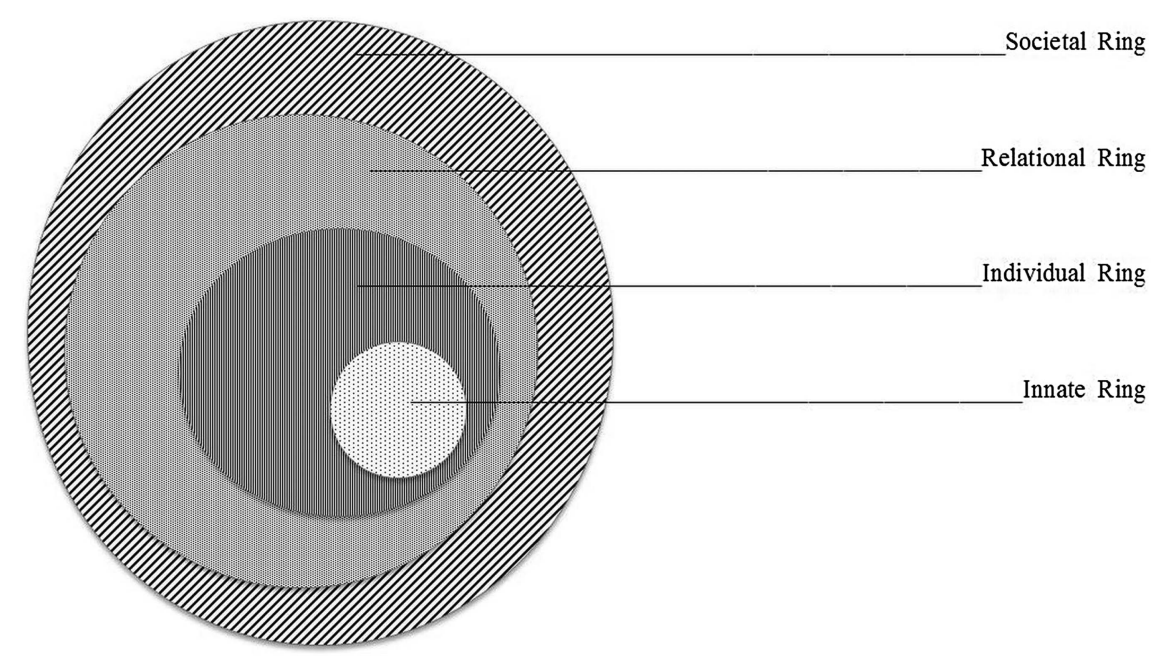

sometimes even paid carers. It is the patient who determines which relationships are to be housed in their own relational ring.

Another important facet of the relational ring is the entwined nature or the 'reciprocity' of these ties. Here individuals whose relationships with the patient are housed in the patient's relational ring also have their relationship with the patient in their own relational rings. This 'reciprocity' creates entwined interests in preserving the patient's personhood in a manner that is consistent with the patient's own views and reputation given that any dishonour affecting the patient will also affect those who share a reciprocal relationship with the patient. This concept of reciprocity owes much to Confucian and other family centric perspectives of personhood. ${ }^{8-11}$

Defining how those within the relational ring conduct and support the patient in their periods of incompetence is the societal ring. The societal ring contains the professional, legal and institutional standards of care and community, religious and cultural beliefs of the society in which the patient is in. This last ring ensures that even when there are no family members present, the patient is cared for in a manner that is consistent with their beliefs and values and in keeping with prevailing sociocultural beliefs and care standards. The societal ring also houses those relationships that are deemed not to be integral to the patient such as those of colleagues, acquaintances and professional 'contacts'.

This holistic concept of personhood is consistent with case reports and the results of studies carried out among cancer sufferers in Singapore. ${ }^{8-11}$ It is on this ethically sensitive, clinically relevant, culturally appropriate framework that we will base the wider effect and importance of the palliative rehabilitation within the end-of-life care setting.

\section{CASE PRESENTATION}

We present a case of a 61-year-old Chinese woman who was diagnosed with a left renal cell carcinoma in July 2013 after she presented with haemorrhagic cystitis. Although the patient underwent a left nephrectomy and adrenalectomy, she declined chemotherapy and radiotherapy. In November 2013, the patient presented with a recurrence of her cancer at the surgical bed, lung metastases, spinal involvement of her 11th thoracic vertebrae to her 1st lumbar vertebrae and brain metastases. Despite a protracted course of steroids and pazopanib and radiotherapy to her brain and spine, she experienced a loss of lower limb power and significant lower limb pain. This in turn led to significant existential, physical, social and psychological distress for the patient as well as her family. This situation was compounded by her unhappiness with her hospital surroundings and her on-going social concerns. In an effort to attenuate some of this distress and provide her with more rehabilitative and psychosocial support she was transferred to a hospice.

\section{Social history}

The patient was a pharmacy assistant married to a 65-year-old accounts clerk at a local transport company. They lived together in a three bedroom flat with their two adult children. Their elder daughter was 32 years old and an unmarried hair stylist while their 26-year-old son had just received a scholarship to John Hopkins University in Baltimore for his further studies in biomedical technology.

At the root of our patient's concerns was her husband and daughter's turbulent relationship, who were now no longer on talking terms, which was compounded by her son's wish to defer his studies in America. The patient was concerned that her son's decision would jeopardise his scholarship. She was also distressed at the lack of support from her eight siblings. As the youngest in the family, the patient had been used to being doted on by her siblings and was left bemused and distraught at what she felt was their sudden disengagement.

In addition, our patient was also finding it hard to come to terms with the significant impairments to her functioning. Her pain and weakness inhibited her ability to self-care and this depressed her. She had always been an active person who rarely asked for help. To find her completely reliant on others and being unable to ambulate potentially permanently was difficult for her to face. Her low mood also left her poorly motivated to communicate and this was compounded by the effects of her analgesics.

\section{INVESTIGATIONS}

A multidimensional palliative care assessment was carried out when the patient was admitted to the hospice. The key findings were that her pain in lower limbs was neuropathic in nature and while a combination of gabapentin, morphine, paracetamol and steroids had helped, she was still having pain on movement and was drowsy most of the time. Both symptoms responded to an escalation in both the breakthrough doses of opioids and the background dose of gabapentin and a reduction in her background opioid dose. It was only then that she would engage in conversations with the social worker, psychologists, the 
physiotherapists, the occupational therapists and our psychospiritual team.

Given that the primary issue that was affecting the patient was her feeling that she was less than the person she was before, we summarise the findings conversation with her and illustrate their impact on her and her family using the Ring Theory. ${ }^{8-11}$

\section{Innate ring}

The patient was born a Christian and had embraced its teachings with great vigour some 15 years ago following the death of a close friend. Yet despite her strong faith she struggled to accept the serious changes to her life that had resulted from this sudden recurrence. She was 'angry' with God and had 'lost' her faith. She turned away visitors of her church and maintained that she was now an atheist.

This change reflected significant changes on her innate ring and provides an opportunity to elaborate on the understanding of the innate ring. The innate ring is composed of two rings. The first is the core and represents the belief that personhood is defined by either the patient's ties with the divine or as a result of possessing human characteristics. This ring is unchanging and is only lost with the patient's demise.

A ring encapsulating the core represents the secondary elements of innate personhood. It contains the beliefs, values and norms that the patient is born into. These facets are changeable and in our patient's case, the ring contracted with her loss of faith and the abandonment of her familial values and religious roots.

\section{Individual personhood}

The loss of independence led the patient to become low in mood, compromising her ability to express her feelings, communicate her thoughts and critically to communicate with her family and friends. She was no longer able to show her affection and empathise with her daughter's distress or her son's anxieties despite being started on antidepressants some 2 months prior to her admission to the hospice.

While she did not lose her competence, her autonomy was hindered by her physical limitations and mood disturbances due to the circumstances that she found herself in. This compromised her individual ring.

\section{Relational personhood}

The loss of faith and her refusal to engage with her church friends who were her closest friends and confidantes significantly attenuated her relational ring with many of these relationships being relegated to her societal ring after being deemed no longer important to her. Similarly many of her siblings were relegated from her relational ring leaving only a handful relationships within her relational ring.

This contraction of her relational ring also provides an insight into how the various rings interact with one another. Changes in our patient's individual and innate rings have a significant impact on the constituents of her relational ring. Similarly her societal ring was also compromised with her lack of engagement with her family and wider community, which in turn decreased in size.

\section{Societal personhood}

Aside from the relationships that are not deemed meaningful to her, our patient's societal ring ensured that even with no family members present, she continues to be cared for in a manner that is in keeping with institutional standards, professional and legal standards and societal and cultural expectations.

\section{TREATMENT}

All aspects of the patient's personhood appear to have been affected by the combination of her pain, loss of function and low mood. As a result, treatment was designed to address this triumvirate of concerns.

To begin with addressing her neuropathic pain through careful titration of neuropathic agents and readjustment of her opioids not only improved her sleeping patterns but also improved her exercise tolerance. In combination with psychospiritual support, counselling and a perceptible improvement in her mobility, this treatment programme also improved her mood.

For the patient, it was her rehabilitation and improved selfcare that made the most difference to her, her outlook and mood. To begin with, regaining her sitting balance and being able to eat and conduct conversations in a sitting position was key. Here her physiotherapy and occupational therapist input was critical not simply for the physical support it provided her but in the realistic goal setting that was part of their treatment strategy. The patient later commented that this approach helped address her suffering and loss of dignity, which in turn improved her mood and helped her re-engage in her previous roles and ties.

\section{Suffering}

According to Beng et al's classifications of suffering among palliative care patients, our patient's suffering took four forms. This related to differential suffering which was 'related to change and loss', dependence suffering which was due to being dependent on others for 'activities of daily living or instrumental activities', empathic suffering which arose as a result of watching family members contend with the physical demands of her care and environmental suffering which arose largely as a result of the limitations forced on her due to restrictions in her mobility in the hospital setting. ${ }^{14}$ All four forms of suffering responded well to the intense rehabilitation that our patient received.

Without creating unrealistic and false hopes of recovery for the patient and family and through the careful maximisation of her abilities within the confines of her clinical limitations brought on by her underlying disease and comorbidities such as anorexia, lethargy, drowsiness and low mood which restrict participation, our patient was better able to care for herself and increase her independence while coming to terms with her condition. Her improvements in her capabilities and mood reduced her family's distress and ameliorated her concerns with regards to them and how they were coping. Further through the employ of a wheel chair and being able to transfer from her bed to a chair using a 'banana board' her feeling of being 'imprisoned' in the hospice, receded.

Being able to support the emotional needs of her two children and still provide counsel and emotional support for her husband allowed the patient to fulfil the role she most desired to play. This in turn allowed her to 'reclaim her self worth' and dignity.

\section{Dignity}

A key consideration associated with self-worth and personhood is the maintenance of dignity. Beng et $a l^{14}$ evidenced that many patients measured their dignity by the manner that their family and loved ones regard them. Here, the patient was more reassured in being able to fulfil her central roles, care for herself and feel less like a burden to her family and as a result 


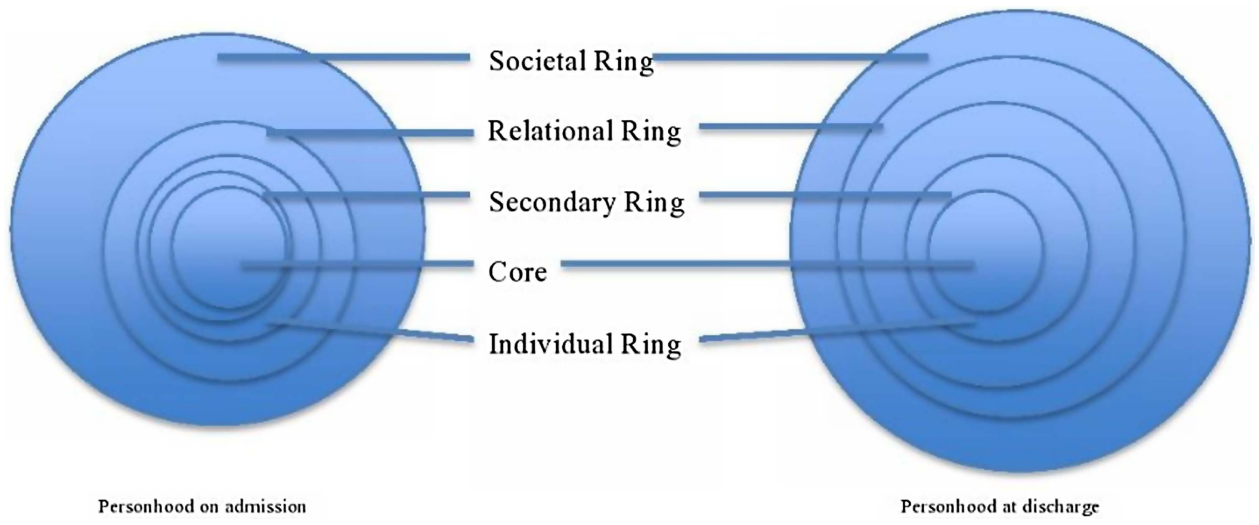

Figure 2 The changing nature of personhood as a result of holistic care.

reclaimed some of her dignity that she felt was lost when she was dependent on others for her basic care needs.

\section{OUTCOME AND FOLLOW-UP}

It is clear that at the start of her stay in the hospice, the patient's personhood, dignity and indeed quality of life were severely compromised. It was her rehabilitation in tandem with the input from the social workers, psychologists, physiotherapists, occupational therapists and our psychospiritual team that allowed her to regain her personhood and restore her dignity and ameliorate her suffering.

While she never regained full function, the employ of supportive measures allowed the patient to reconnect with her family and even with her church group.

\section{DISCUSSION}

The role of palliative rehabilitation in the preservation of the patient's personhood cannot be underestimated and provides yet further evidence to its critical role in the provision of holistic end-of-life care.

The combination of focused palliative rehabilitation that is practiced within the specific confines of a particular patient's clinical, psychological and existential limitations allows for the reconstitution of a patient's self-esteem, dignity and personhood. In our patient's case, her rehabilitation allowed her to reassert her individual personhood. This in turn allowed her to once again manifest her true personality and assert her own values, wishes and beliefs. This re-establishment of her

\section{Learning points}

- The employ of rehabilitation in the end-of-life care can help some patients retain their personhood.

- The employ of palliative rehabilitation must be custom designed for each patient to suit their particular situation and needs.

- Rehabilitation in the end of life must be seen as a part of effective multidimensional appraisal and care. individual ring allowed, through the inter-related nature of the rings within the Ring Theory, for the re-establishment of her relational ring and the regeneration of her societal ring.

The ability to connect with others and assert her independence through appropriate treatment allowed the patient the chance to also reinvigorate her secondary ring and rejuvenate her spiritual beliefs (figure 2).

Clearly palliative rehabilitation can only be effective for certain patients and must be seen as part of a holistic approach yet its role in the overall practice of palliative care cannot be ignored.

Competing interests None.

Patient consent Obtained.

Provenance and peer review Not commissioned; externally peer reviewed.

\section{REFERENCES}

1 Tookman A, Eades J. Rehabilitation approaches in Walsh D, et al. palliative medicine. London: Saunders Elsevier, 2009:1389-94.

2 Barawid E, Covarrubias N, Tribuzio B, et al. The benefits of rehabilitation for palliative care patients. Am J Hosp Palliat Care 2013. doi: 10.1177/ 1049909113514474

3 Desai MJ, Kim A, Fall PC, et al. Optimizing quality of life through palliative care. J Am Osteopath Assoc 2007;107(12 Suppl 7):ES9-14.

4 Yoshioka H. Rehabilitation for the terminal cancer patient. Am J Phys Med Rehabil 1994;73:199-206.

5 Roe JWG, Leslie P. Beginning of the end? Ending the therapeutic relationship in palliative care. Int J Speech Lang Pathol 2010;12:304-8.

6 Cheville A. Rehabilitation of patients with advanced cancer. Cancer 2001; 92(4 Suppl):1039-48

7 Dietz J. Rehabilitation oncology. New York: John Wiley \& Sons, 1981.

8 Radha Krishna LK. Personhood within the context of sedation at the end of life in Singapore. BMJ Case Rep 2013:pii:bcr2013009264. doi: 10.1136/ bcr-2013-009264

9 Krishna LKR, Alsuwaigh R, Sim SW. Ring Theory of Personhood. Am J Hosp Palliat Care. Published Online First: 13 August 2013

10 Krishna LKR. Accounting for personhood in palliative sedation: the Ring Theory of Personhood. Med Humanit 2014;40:17-21.

11 Krishna LK, Alsuwaigh R. Understanding the Fluid Nature of Personhood-the Ring Theory of Personhood. Bioethics 2014. doi: 10.1111/bioe.12085.

12 Chochinov HM. Dignity-conserving care-a new model for palliative care: helping the patient feel valued. JAMA 2002;287:2253-60.

$13 \mathrm{Ho}$ AH, Leung PP, Tse DM, et al. Dignity amidst liminality: healing within suffering among Chinese terminal cancer patients. Death Stud 2013;37:953-70.

14 Beng TS, Guan NC, Seang LK, et al. The experiences of suffering of palliative care patients in Malaysia: a thematic analysis. Am J Hosp Palliat Care 2014;31:45-56. 
Copyright 2014 BMJ Publishing Group. All rights reserved. For permission to reuse any of this content visit http://group.bmj.com/group/rights-licensing/permissions.

BMJ Case Report Fellows may re-use this article for personal use and teaching without any further permission.

Become a Fellow of BMJ Case Reports today and you can:

- Submit as many cases as you like

- Enjoy fast sympathetic peer review and rapid publication of accepted articles

- Access all the published articles

- Re-use any of the published material for personal use and teaching without further permission

For information on Institutional Fellowships contact consortiasales@bmjgroup.com

Visit casereports.bmj.com for more articles like this and to become a Fellow 